Nagulu et al., 2009

Stamford Journal of

\section{Development and Validation of Rapid and Sensitive HPLC Method for the Determination of Methotrexate in Human Serum}

\author{
M. Nagulu ${ }^{1 *}$, V. Uday Kiran ${ }^{1}$, Y. Narsimha Reddy ${ }^{1}$, D. Rama Krishna ${ }^{1}$ \\ Department of Pharmacology and Clinical Pharmacy ${ }^{1}$ \\ University College of Pharmaceutical Sciences \\ Kakatiya University, Warangal -506 009 \\ Andhra Pradesh, India
}

\author{
*Corresponding Author \\ M. Nagulu \\ Associate Professor \\ Dept. of Pharmacology and Clinical \\ Pharmacy, Vagdevi College of \\ Pharmaceutical Sciences, Kakatiya \\ University, India \\ E-mail: nagoncology@gmail.com
}

\begin{abstract}
Methotrexate competitively inhibits dihydrofolic acid reductase and thereby inhibits DNA synthesis and cellular replication. This study describes a simple and fast high-performance liquid chromatography method for the determination of methotrexate [MTX] in serum.samples were collected from adult cancer patients receiving high dose MTX at Mahathma Gandhi Memorial hospital (Warangal,AP.India) at various time intervals after the end of each infusion. Serum was deproteinized with trichloroacetic acid and the supernatant was injected into a $250 \times 4.6 \mathrm{~mm}$ octadecylsilane column. Mobile phase was made of TRIS-phosphate buffer (pH 5.7): methanol: acetonitrile (70:20:10) with a flow rate of $1 \mathrm{ml} / \mathrm{min}$. Ultraviolet detection was done at 313 $\mathrm{nm}$ and at ambient temperature. Para aminoacetophenone was used as internal standard. Methotrexate and internal standard retention times were 4.6 and 9.5 minutes, respectively. Results showed that reproducibility (precision) of method within a day was 2.6 to 6 percent and between days was 5.5 to 9.5 percent. The recovery of the method was between 61.5 and 72.7 percent. The quantitation limit of the method for methotrexate was $0.1 \mu \mathrm{M}$. This method is suitable for quantitation of methotrexate after infusion of high doses of this drug and has good accuracy, precision and quantitation limit.
\end{abstract}

Key Words: Methotrexate; HPLC; Serum Concentration.

\title{
INTRODUCTION
}

Methotrexate (MTX) formerly known as amethopterin, is an antimetabolite and antifolate drug used in treatment of cancer and autoimmune diseases. It acts by inhibiting the metabolism of folic acid. Methotrexate is a weak dicarboxylic acid with pKa 4.8 and 5.5 , and thus it is mostly ionized at physiologic $\mathrm{pH}$. Methotrexate is metabolized by intestinal bacteria to the inactive metabolite 4amino-4-deoxy-N-methylpteroic acid (DAMPA) and accounts for less than $5 \%$ loss of the oral dose.It can be taken orally or administered by injection (subcutaneous, intramuscular, intravenous or intrathecal). Methotrexate concentration in plasma and other biological fluids is determined to study its pharmacokinetics and also to predict and prevent its toxicity when administered in high dose intravenous infusion of the drug by modification of the calcium folinate administration schedule according to the plasma concentration of methotrexate (Boyd, 1992, Fleisher, 1993, Dollery, 1991. Different methods have been described for the determination of methotrexate in plasma and other biological fluids including enzyme inhibition methods, radiometry and radio immunoassay, enzyme multiple immunoassay technique (EMIT), fluorescence polarization immunoassay (FPIA) (Assadullahi et al., 1991) and high performance liquid chromatography (HPLC) (Schilsky, 1983).

The aim of our study is to describe a simple, fast, accurate and precise method for the determination of methotrexate in serum for pharmacokinetic studies and routine therapeutic drug monitoring in high-dose intravenous infusion of this drug. 


\section{MATERIALS \& METHODS}

\section{Chemicals}

Methotrexate(+)-amethopterine, $(>98.5 \%$ purity for HPLC) and P-aminoacetophenone were purchased from Sigma Aldrich(USA).Methanol and acetonitrile (Merck,Germany), trichloroaceticacid (Himedia,India), TRIS (trishydroxymethyl-aminomethane (Merck, Germany), sodium dihydrogen phosphate, $\mathrm{H}_{2} \mathrm{O}_{2}$ (Himedia, India) were all analytical grade.

\section{Chromatographic Conditions}

A Schimadzu liquid chromatography system equipped with a LT 10AT VP pump, a SPD 10A VP variable wavelength UVvisible spectrophotometric detector and a Rheodyne 20 microliter loop injector system was used(Schimadzu, Kyoto, Japan). INERTSIL ODS-3V C-18, 4.6x250mm [GL sciences Inc, Japan] chromatography column was used for analysis.

The mobile phase consisted of phosphate -TRIS buffer $(0.1 \mathrm{M}$ dihydrogen phosphate and $0.01 \mathrm{M}$ TRIS; pH 5.7): methanol: acetonitrile, with the ratio of $70: 20: 10$, respectively. The flow rate was $1 \mathrm{ml} /$ minute and the eluent was monitored spectrophotometrically at $313 \mathrm{~nm}$ at room temperature.

\section{Solutions of External and Internal Standards}

Due to the possible instability of methotrexate in aqueous phosphate buffer solutions (Connors et al., 1986), a stock standard solution of methotrexate $(10000 \mu \mathrm{M} / \mathrm{ml})$ was prepared using $0.1 \mathrm{~N}$ sodium hydroxide. Stock solutions of internal standard ( $p$-aminoacetophenone) were also prepared in the same solvent at the concentrations of $5 \mu \mathrm{g} / \mathrm{ml}$. Further dilution of methotrexate stock solution was done with drug free plasma to prepare different concentrations of methotrexate $(5,10,30,50$ and $70 \mu \mathrm{M} / \mathrm{ml}$ ) (Abdolhosein et al., 2003). Sample collection and preparation: Received methotrexate at doses of $16 \mathrm{mg} / \mathrm{m} 2$ as 4 or 6 hours small infusions, as part of protocols for the treatment of various cancer diseases at Mahathma Gandhi memorial [MGM] Hospital (Kakatiya medical college, Warangal, india). Blood samples were collected at various times after the end of each infusion. To each $100 \mu \mathrm{L}$ of patient's or standard sample, $100 \mu \mathrm{L}$ of stock solutions of internal standard $5 \mu \mathrm{g} / \mathrm{mL}$ was added to samples with methotrexate concentration of above and lees than $5 \mu \mathrm{m}$, respect After complete mixing of samples with internal standard, $40 \mu \mathrm{L}$ of trichloroacetic acid ( $2 \mathrm{M}$ in ethanol) was added and vortex mixed for 2 minutes, then centrifuged at $3000 \mathrm{rpm}$ for 15 minutes. 10 or $20 \mu \mathrm{L}$ aliquots of the supernatant was directly injected into the chromatography column. Each sample was analyzed in duplicate. All samples or standard solutions were stored at $-80^{\circ} \mathrm{C}$ until analyzed.

\section{Recovery and Precision}

The recovery was studied by preparation of the various amounts of MTX in blank plasma (spiked blank). MTX was determined according to the described method. The recovery was calculated by comparison of the found amounts with the added ones.

\section{RESULTS}

Under the conditions used for the chromatography, the retention times for methotrexate and the internal standard were $4.6 \pm 0.03$ and $9.5 \pm 0.98$ minutes, respectively. Figure- 1 shows the chromatograms of human blank plasma used for preparation of different concentrations of methotrexate standard solution (Boyd, 1992) and patients samples (Fleisher, 1993) withdrawn from patients who received $16 \mathrm{mg} / \mathrm{sqm}$ of methotrexate as a 4-h infusion. The chromatographic condition employed was quite specific for methotrexate and paminoacetophenone. Other drugs that might be administered concomitantly with methotrexate such as leucovorine, adriamycin, bleomycin, cyclophosphamide, mercaptopurine, vincristine, metocloperamide, prednisolone, diazepam, aspirin and trimethoprim-sulfamethoxazole could not interfere with MTX Peaks because either they have no significant absorption at $313 \mathrm{~nm}$ or their retention times are quite different. This fact was proved in this study by adding each of these drugs to plasma samples containing methotrexate and analyzed by chromatography. 

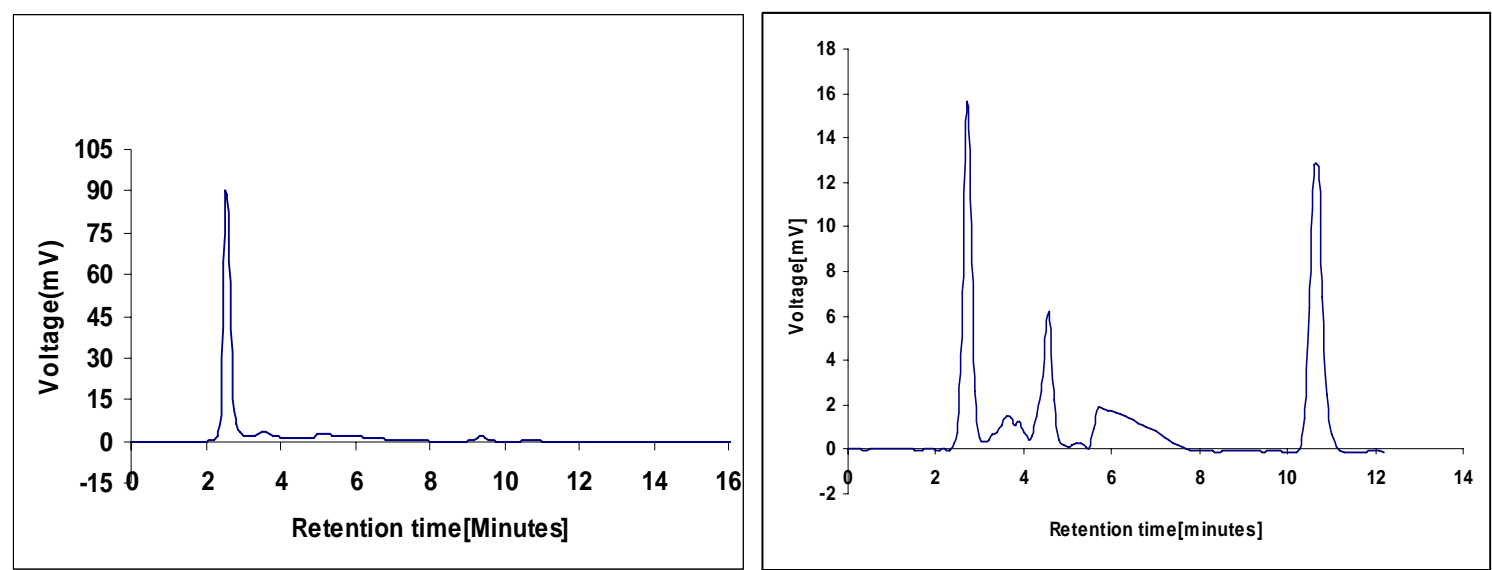

Figure- 1: Human Blank serum

Figure- 2: Serum sample spiked with $\mu \mathrm{M} / \mathrm{ml}$ MTX [methotrexate] and PAAS [Para amino acetophenone]

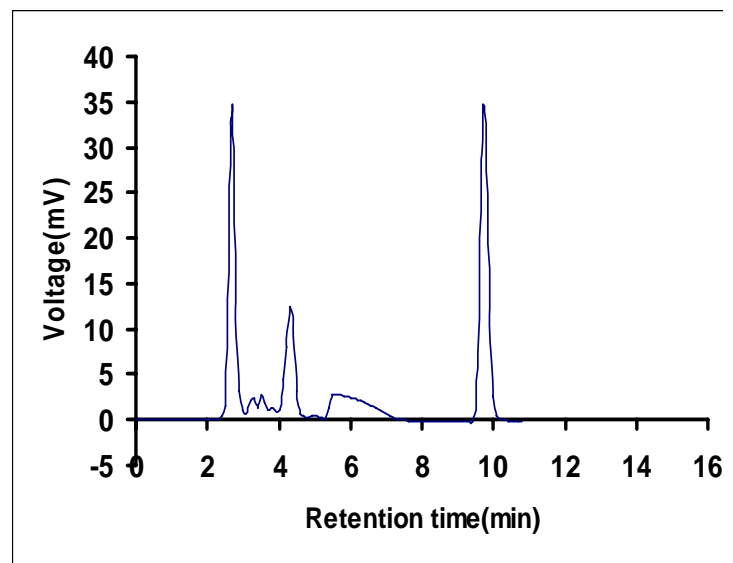

Figure- 3: MTX and IS [PAAS] in patient serum sample, at $10 \mathrm{~min}$ after $4 \mathrm{~h}$ infusion

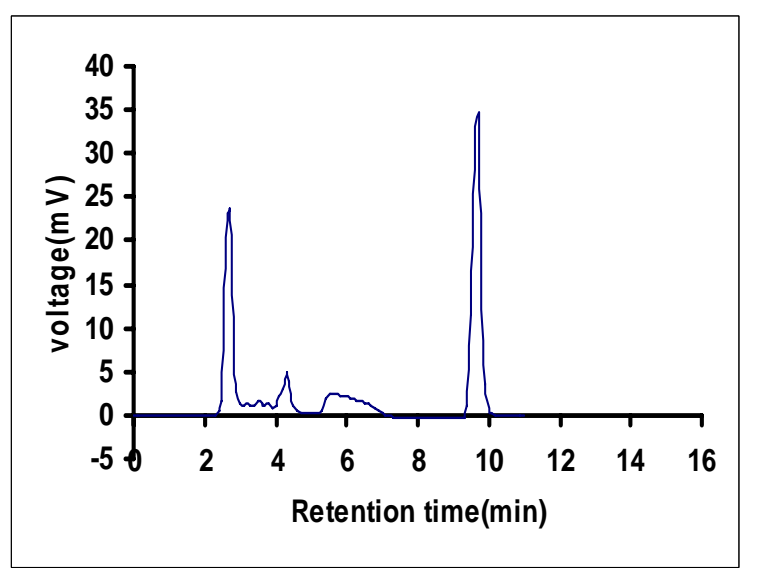

Figure- 4: MTX and IS [PAAS] in patient serum sample, at $30 \mathrm{~min}$ after $4 \mathrm{~h}$ infusion

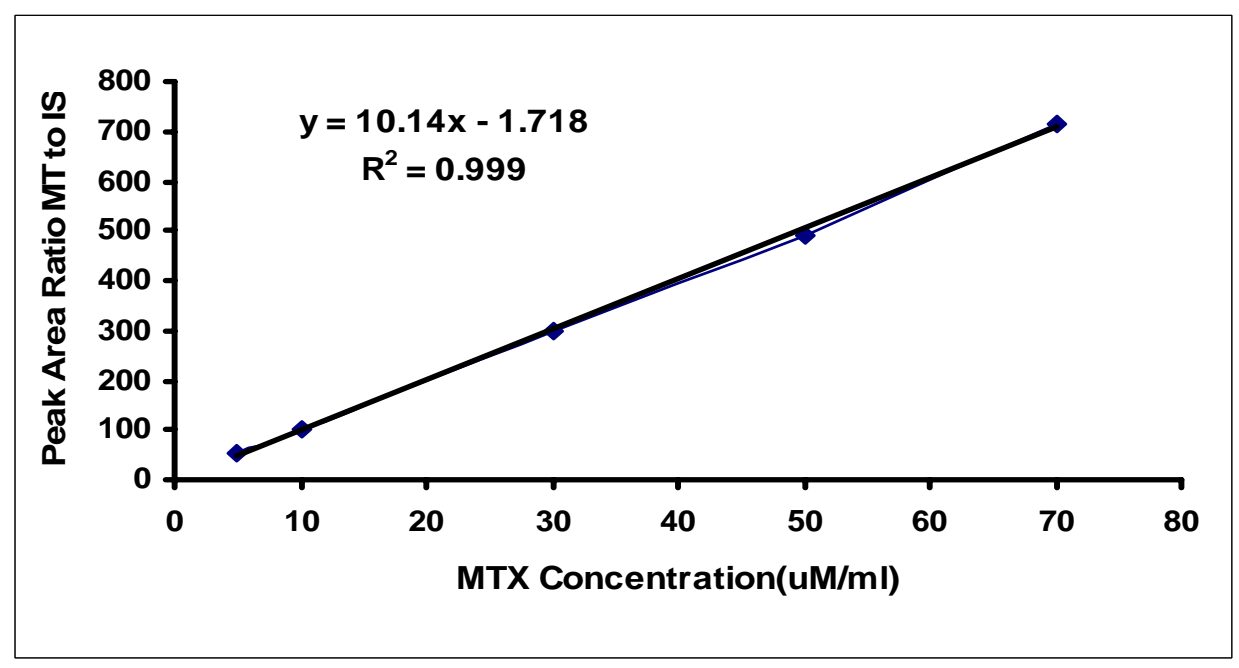

Figure- 5: Linear standard curve determination of methotrexate in serum (concentration range $5-70 \mu \mathrm{M} / \mathrm{ml}$ ) 
According to the previous reports, the major and most important metabolite of methotrexate is 7hydroxymethotrexate but its pharmacological effect is not significant (Breithaupt et al.,1982; Brimmed et al.,1987; Farid et al.,1983). We did not have any pure standard of this metabolite and unable to obtain it from elsewhere, therefore it was not possible to identify its retention time positively and to quantitate its concentration in plasma. In order to determine plasma concentration of methotrexate, internal standardization method was used. After preparation of various concentrations of methotrexate and analyzing chromatography each standard solution, two standard curves were prepared by plotting the ratio of peak area of methotrexate to internal standard ( $p$-aminoacetophenone) versus concentration of methotrexate. A good linearity was seen for both the standard curves (Figure-1, 2). To assess the accuracy of the method, recovery of methotrexate from plasma samples with known concentrations was compared with the solutions of methotrexate at the same concentrations as shown in Table-1. For the assessment of method precision, reproducibility of the results obtained for different concentrations of methotrexate was determined at 5 different days and 5 times in one day. The results of reproducibility study are shown in Table 2 as recovery and accuracy determination. The limit of quantitation of methotrexate in plasma with the above sample pretreatment method was $5 \mu \mathrm{M}$.

Table -1:

\begin{tabular}{|c|c|c|c|c|}
\hline \multirow{2}{*}{ Spiked concentration $(\mu \mathrm{M} / \mathrm{ml})$} & \multirow{2}{*}{ Day } & \multicolumn{3}{|c|}{ Measured Concentration } \\
\hline & & Mean $(\mu \mathrm{M} / \mathrm{ml})$ & SD & RSD \\
\hline \multicolumn{5}{|l|}{ Inter-day variation } \\
\hline \multirow[t]{4}{*}{5} & 1 & 4.8 & 0.080 & 1.667 \\
\hline & 2 & 4.9 & 0.100 & 2.041 \\
\hline & 3 & 5.1 & 0.096 & 1.882 \\
\hline & 4 & 5.21 & 0.030 & 0.576 \\
\hline \multirow[t]{4}{*}{30} & 1 & 31.20 & 0.650 & 2.083 \\
\hline & 2 & 29.80 & 0.120 & 0.403 \\
\hline & 3 & 30.36 & 0.050 & 0.165 \\
\hline & 4 & 32.60 & 0.960 & 2.945 \\
\hline \multirow[t]{4}{*}{70} & 1 & 69.32 & 0.960 & 1.385 \\
\hline & 2 & 70.15 & 0.069 & 0.098 \\
\hline & 3 & 69.99 & 0.870 & 1.243 \\
\hline & 4 & 68.95 & 0.050 & 0.073 \\
\hline Intra-day variation & & & & \\
\hline 5 & & 5.10 & 0.15 & 2.941 \\
\hline 30 & & 29.60 & 0.97 & 3.277 \\
\hline 70 & & 70.26 & 0.12 & 0.171 \\
\hline
\end{tabular}

SD: Standard deviation, RSD: Relative standard deviation and mean value of 4 determinations

Table- 2: Assessment of Recovery and Accuracy determination of MTX in human serum

\begin{tabular}{|c|c|c|c|}
\hline Substance & Concentration & $\begin{array}{c}\text { Recovery (\%) } \\
\text { Mean } \pm \text { SD }\end{array}$ & $\begin{array}{c}\text { Accuracy (\%) } \\
\text { Mean } \pm \text { SD }\end{array}$ \\
\hline MTX & $5(\mu \mathrm{M})$ & $98 \pm 2.8$ & $100.06 \pm 1.9$ \\
MTX & $30(\mu \mathrm{M})$ & $98.08 \pm 4.04$ & $97.7 \pm 1.07$ \\
MTX & $70(\mu \mathrm{M})$ & $99.98 \pm 0.80$ & $99.8 \pm .77$ \\
Internal Standard & $5(\mu \mathrm{g} / \mathrm{ml})$ & $96.35 \pm 1.02$ & $96.69 \pm 1.03$ \\
\hline
\end{tabular}

SD: Standard deviation and mean value of 5 determinations 


\section{DISCUSSION}

Various methods of high-performance liquid chromatography for the determination of methotrexate in biological fluids have been described so far which differ in chromatography type (reverse phase or ion-pair chromatography) or detection system (UV or fluorescence) (Cosolo et al., 1981). Reverse-phase high performance liquid chromatography with UV detection has been most recommended (Lawson et al., 1981, Najjar et al., 1981). But, an important point is that most of them are tedious and expensive because they use more material and have many stages of experiment. Besides, they are not suitable for a routine and quick therapeutic drug monitoring (TDM) test which is necessary for a child cancer patient in a high dose infusion therapy at hospital, or reference laboratories.

In this article a simple and fast method for the determination of methotrexate in serum is described that has equal precision and accuracy to other similar methods (Salamoun et al., 1986; Skoglund et al., 1994). A full chromatography takes 10 minutes. To include sample preparation time it may need 25 minutes for the whole of each analysis, which is comparatively a short time. The short duration of assay time is of quite importance in routine monitoring of the drug in serum to predict and prevent future toxicity in high-dose methotrexate intravenous infusion. On the other hand this method has a satisfactory quantitation limit that makes it ideal for pharmacokinetic studies and therapeutic drug monitoring of methotrexate after the administration of high doses of this drug. To improve the quantitation limit further we could use solid phase extraction technique along with fluorescence detection after post column derivitization of the methotrexate to fluorescent compounds so that the method become suitable for determination of methotrexate after the administration of lower doses of the drug but such methods are more tedious, time consuming and expensive.

\section{CONCLUSION}

A one step extraction procedure for methotrexate from serum and an improved method for determination of methotrexate are reported. Compared to previously published methods, the suggested extraction procedure is considerably more simple, rapid, reliable and sensitive. The HPLC technique based on UV detection is suitable for determination of small amounts of methotrexate with good accuracy and reproducibility .Simple sample preparation procedure and a relatively short chromatographic time make this method suitable for processing of multiple samples in a limited amount of time for pharmacokinetic studies

\section{ACKNOWLEDGEMENTS}

The authors are grateful to UGC-India for their financial assistance.

\section{REFERENCES}

Abdolhosein M, Ahmad ZM, Saeid R, Mohamad P(2003).High-Performance Liquid Chromatography Determination of Methotrexate in Plasma. Iranian Journal of Pharmaceutical Research, 18 (2):149-152.

Assadullahi TP, Dalgi E, Warner JO. (1991) High performance liquid chromatography method for serum methotrexate levels in children with steroid dependent asthma. J. Chromatogr.565: 349-356

Boyd JR. (1992) (Ed) Drugs Facts and Comparisons, JP Lippincot Company, St. Louis ,653-654

Breithaupt H, Kuenzelen E, Goebel G.(1982) Rapid high-performance liquid chromatographic determination of methotrexate and its metabolites 7- hydroxyl methotrexate and 2,4diamino-N10-methyl pteroic acid in biological fluids. Anal. Biochem.127: 103-113

Brimmed PA, Sams DJ. (1987) Rapid and simple assay for the measurement of methotrexate in serum, urine and red blood cells by reversed-phase high performance liquid chromatography. J. Chromatogr. 413: 320-325 
Connors KA, Amidon GL, Stella VJ. (1986) Chemical Stability of Pharmaceuticals: A Handbook for Pharmacists. John Wiley and Sons Inc., New York. 561-576

Cosolo W, Drummer OH, Christophidis N. (1981) Comparison of high-performance liquid chromatography and the Abbott fluorescent polarization radioimmunoassay in the measurement of methotrexate J. Chromatogr. 223,225-231.

Dollery C. (Ed) (1991).Therapeutic Drugs. Vol. 2, Churchill Livingston, London M101-M110.

Farid YZ, Watson ID, Stewart MJ. (1983) An assay for methotrexate and its metabolites in serum and urine by ion-pair high-performance liquid chromatography. J. Pharm. Biomed. Anal.1: 55-63

Fleisher M.(1993) Antifolate analogs: mechanism of actions, analytical methodology, and clinical efficacy ,Ther.Drug Monit. 15,521-529

Lawson GJ,Dixon PF (1981) Rapid and simple method for measurement of methotrexate and 7hydroxymethotrexate in serum by high-performance liquid chromatography. $\mathrm{J}$. Chromatogr. 223, 225-231.

Najjar TA, Matar KM,Alfawaz IM. (1991) Comparison of a new high-performance chromatography with fluorescence polarization immunoassay for analysis of methotrexate. Ther. Drug Monit.14: 142-146

Salamoun J, Frantsiek J. (1986). Determination of methotrexate and its metabolites 7hydroxymethotrexate and 2,4-diamino-N10-methyl pteroic acid in biological fluid by liquid chromatography with fluorimetric detection. J. Chromatogr.378: 173-181.

Schilsky RL. (1983) Clinical pharmacology of methotrexate. In: A.M.Ame, G.Powis and I.S.Kovash (Eds) Pharmacokinetics of Anticancer Agents in Humans. Elsevier Science Publishers, New York.p187- 205.

Skoglund KA, Soderhall S,Beck O. (1994) Plasma and urine levels of methotrexate and 7hydroxymethotrexate in children with ALL during maintenance therapy with weekly oral methotrexate .Med. Pediatr. Oncol. 22 :187- 193. 